Check for updates

Cite this: RSC Adv., 2019, 9, 27684

\title{
High-performance and stable $\mathrm{CsPbBr}_{3}$ light- emitting diodes based on polymer additive treatment $\uparrow$
}

\author{
Wanqing Cai, ${ }^{a}$ Ziming Chen, ${ }^{\star a}$ Dongcheng Chen, ${ }^{a}$ Shijian Su, (D) a Qinghua Xu, ${ }^{\text {b }}$ \\ Hin-Lap Yip (D) *ac and Yong Cao ${ }^{a}$
}

\begin{abstract}
Because of their high efficiency and sharp emission, perovskite light-emitting diodes are a promising candidate for next-generation lighting techniques. However, the relatively poor stability of perovskite light-emitting diodes lowers their utility. Therefore, a highly stable perovskite light-emitting diode has to be developed to meet the commercial demand. Herein, we report a highly stable $\mathrm{CsPbBr}_{3}$ light-emitting diode via simple polymer treatment. The addition of 2-methyl-2-oxazoline in perovskite film assists the formation of $\mathrm{CsPbBr}_{3}$ nanocrystals, improving the quality and photoluminescence property of perovskite film. Based on such $\mathrm{CsPbBr}_{3}$ nanocrystals and polymer hybrid film, our device presents a high external quantum efficiency and luminance of around $3.0 \%$ and $16648 \mathrm{~cd} \mathrm{~m}^{-2}$, respectively. Moreover, an excellent device half-lifetime of more than 2.4 hours has been achieved, under continuous operation at a relatively high initial luminance of $1000 \mathrm{~cd} \mathrm{~m}^{-2}$, representing one of the most stable PeLEDs operated at such high initial luminance.
\end{abstract}

Received 10th July 2019

Accepted 27th August 2019

DOI: 10.1039/c9ra05270d

rsc.li/rsc-advances

thermal degradation even at temperatures below $100{ }^{\circ} \mathrm{C} .{ }^{19-22}$ Also, increasing the annealing time of $\mathrm{MAPbBr}_{3}$ emission layers from 10 to $30 \mathrm{~min}\left(\right.$ at $90^{\circ} \mathrm{C}$ ) causes sublimation of MABr and hence reduces its crystal quality, resulting in degraded performance of $\mathrm{MAPbBr}_{3}$-based PeLEDs. ${ }^{23}$ Therefore, it is crucial to develop emissive layers for LED application with better stability than organic-inorganic hybrid perovskites. Among the perovskite family, all-inorganic halide perovskites such as greenemissive $\mathrm{CsPbBr}_{3}$ have proven much more stable than organic-inorganic hybrid perovskite. ${ }^{24-32}$ For instance, the thermal-decomposition temperature of $\mathrm{CsPbBr}_{3}\left(580{ }^{\circ} \mathrm{C}\right)$ is much higher than that of $\mathrm{MAPbBr}_{3}$, which suggests that $\mathrm{CsPbBr}_{3}$ LEDs may possess superior thermal stability during long-term operation..$^{33}$

In addition, as perovskite crystals in smaller size can provide a better confinement of injected charge carriers and hence display improved light-emitting properties, numerous investigations have studied PeLED based on perovskite nanocrystals. $^{34-42}$ For example, it was found that the addition of a small amount of poly(ethylene oxide) to $\mathrm{CsPbI}_{3}$ system was an effective way to form $\alpha$-phase small-grain $\mathrm{CsPbI}_{3}$ perovskite films at lower annealing temperatures. ${ }^{43}$ This insulating polymer could also passivate the pinholes and reduce the crystal size of $\mathrm{CsPbBr}_{3}$ films, leading to a PeLED with enhanced performance. ${ }^{38,44}$ Also, we have ever reported that introducing the polymer of poly(2-ethyl-2-oxazoline) into $\mathrm{MAPbI}_{3}$ and $\mathrm{CsPbBr} \mathrm{I}_{3-x}$ systems can simultaneously reduce the crystal sizes and trap densities of perovskite films to produce near-infrared and pure-red PeLED with EQEs as high as $5.4 \%$ and $6.55 \%$, 
respectively. ${ }^{25,45}$ Based on these previous reports, it is obvious that a suitable polymer additive can reduce the size of perovskite crystals and improve the overall performance of PeLEDs.

In this study, we combined stable all-inorganic perovskites with crystal size-reducing polymer additives to yield a highly stable $\mathrm{CsPbBr}_{3}$ LED with good device performance. We found that the addition of poly(2-methyl-2-oxazoline) (PMOXA) assisted the formation of both high-quality $\mathrm{CsPbr}_{3}$ nanocrystals and a much stable perovskite phase. Meanwhile, PMOXA could passivate the surface traps of $\mathrm{CsPbBr}_{3}$ nanocrystals and consequently improve the overall photoluminescence quantum yield (PLQY) of the hybrid films. Using these high-quality $\mathrm{CsPbBr}_{3}$ nanocrystal films as an emissive layer, we successfully fabricated a green-emissive PeLED with maximum EQE and luminance of around $3.0 \%$ and $16648 \mathrm{~cd} \mathrm{~m}^{-2}$, respectively, and an excellent device half-lifetime of more than 2.4 hours under continuous operation at a relatively high initial luminance of $1000 \mathrm{~cd} \mathrm{~m}^{-2}$, representing one of the most stable PeLEDs operating at such high initial luminance. Moreover, the device presented an extremely narrow electroluminescence (EL) emission at $512 \mathrm{~nm}$ with a full width at half maximum (FWHM) of $18 \mathrm{~nm}$ and excellent spectrum stability, representing a highquality green emission.

\section{Results and discussion}

As mentioned previously, the addition of polymer additives to perovskite film is a proven method to control perovskite crystal size and improve the resulting film quality. ${ }^{4-48}$ Inspired by these results, we added PMOXA to the $\mathrm{CsPbBr}_{3}$ precursor solutions to control the film morphology and crystal growth during the film formation process. We found that as the concentration of PMOXA in the precursor solution increased, the properties (absorption, photoluminescence [PL] emission, crystal quality and film morphology, etc.) of the resultant perovskite films changed accordingly.

Fig. 1a shows that the absorption edge in pristine $\mathrm{CsPbBr}_{3}$ film is located at approximately $517 \mathrm{~nm}$, but after the addition of PMOXA at concentrations from $5 \%$ to $25 \%$, the absorption edge blue-shifted to approximately $512 \mathrm{~nm}$. A similar phenomenon was also observed in the PL spectra (Fig. 1b), where the PL emission from pristine $\mathrm{CsPbBr}_{3}$ film was located at $517 \mathrm{~nm}$, but after the addition of PMOXA at concentrations from $5 \%$ to $25 \%$, the PL emission of perovskite film blue-shifted $5 \mathrm{~nm}$ to approximately $512 \mathrm{~nm}$. We attributed the blue-shift of absorption and PL spectra after the incorporation of PMOXA to two possible reasons: the trap passivation effect from the PMOXA and the decrease of perovskite crystal sizes that could induce quantum confinement effects. Both aspects are discussed below. $^{25,45}$

$\mathrm{X}$-ray diffraction (XRD) patterns were measured to study the effect of the addition of PMOXA on the crystal structure of $\mathrm{CsPbBr}_{3}$, as shown in Fig. 1c. We observed diffraction peaks at $2 \theta$ of approximately $15.1^{\circ}, 21.5^{\circ}, 30.4^{\circ}$ and $35.4^{\circ}$ that could be assigned to the (100), (110), (200) and (210) planes of the cubic $\alpha-\mathrm{CsPbBr}_{3}$ lattice, respectively. The peak positions were in complete correspondence with the diffraction patterns of the bulk materials obtained from the JCPDS database (no. 540752). ${ }^{49-51}$ We observed that the (100) peak appeared only when PMOXA was added in concentrations between $15 \%$ and $25 \%$, suggesting that PMOXA could assist the formation of highquality $\alpha$-phase $\mathrm{CsPbBr}_{3}$ crystals and modulate their orientation.

Moreover, to understand the influence of PMOXA on the charge recombination properties within $\mathrm{CsPbBr}_{3}$ films, PL decay lifetimes were measured by time-correlated single photon counter, as shown in Fig. 2a. Bi-exponential decay functions (SE1) were fitted to the PL decay curves, where $\tau_{1}$ could be ascribed to the non-radiative recombination of initially photogenerated excitons through trap states, and $\tau_{2}$ corresponded to the bimolecularly radiative recombination of charge carriers. Accordingly, $A_{1}$ and $A_{2}$ were the fractions of the fast $\left(\tau_{1}\right)$ and slow $\left(\tau_{2}\right)$ decay components, respectively. ${ }^{52,53}$ The detailed values of $\tau_{1}, \tau_{2}, A_{1}$, and $A_{2}$ are summarised in Table S1. $\dagger$ We found that average PL lifetimes $\left(\tau_{\text {ave }}\right)$ increased as the PMOXA concentration increased from $0 \%$ to $20 \%$ and decreased as the PMOXA concentration increased to $25 \%$. The longest $\tau_{\text {ave }}$ of 104.7 ns was obtained in 20\% PMOXA-treated $\mathrm{CsPbBr}_{3}$ film, which is much longer than the $\tau_{\text {ave }}$ in pristine $\mathrm{CsPbBr}_{3}$ film (36.1 ns). This result suggests that the addition of PMOXA could dramatically enhance the overall lifetime of photo-generated charge carriers, which would be beneficial to the relatively slow radiative
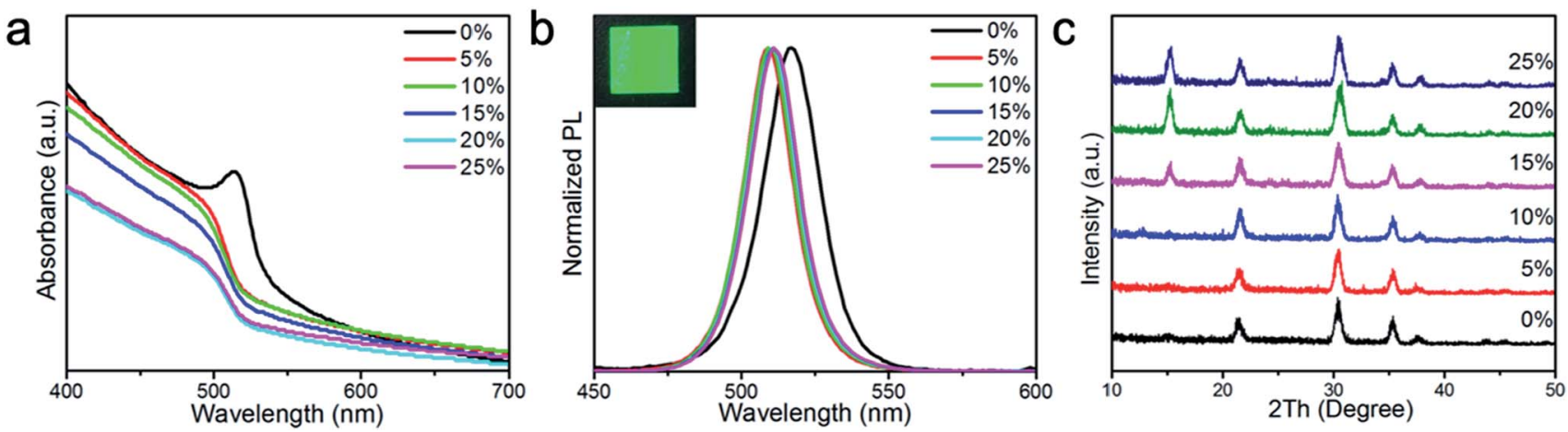

Fig. 1 (a) Absorbances and (b) normalised $\mathrm{PL}$ spectra of $\mathrm{CsPbBr}_{3}$ films with various concentrations of PMOXA. The inserted image is the $20 \%$ PMOXA-treated $\mathrm{CsPbBr}_{3}$ film under UV lamp (365 nm) illumination. (c) XRD patterns of $\mathrm{CsPbBr}_{3}$ films with various concentrations of PMOXA. 

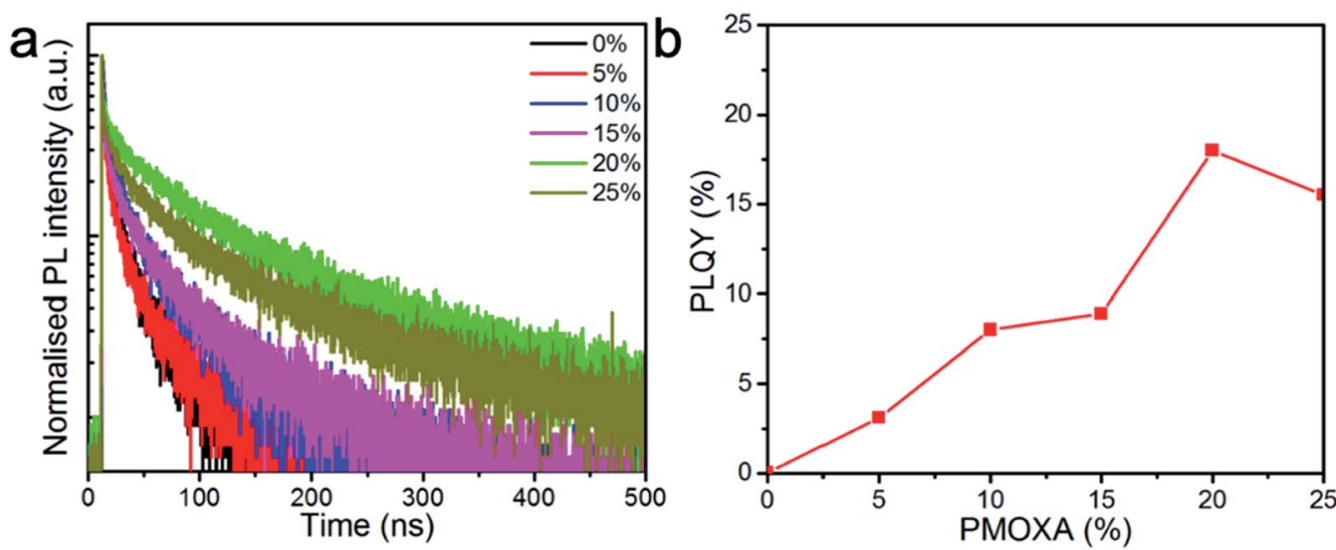

Fig. 2 (a) PL lifetime traced at the emission peak of perovskite films with various concentrations of PMOXA under a fixed excitation fluence of 1 $\mu \mathrm{J} \mathrm{cm}{ }^{-2}$ at the excitation wavelength of $365 \mathrm{~nm}$. (b) PLQYs of $\mathrm{CsPbBr}_{3}$ films with various concentrations of PMOXA (excited at $1 \mathrm{~mW} \mathrm{~cm}^{-2}$ ).

recombination process. Moreover, it is apparent that $A_{1}$ decreased significantly as the PMOXA concentrations increased from $0 \%$ to $20 \%$ and increased when the PMOXA concentration increased to $25 \%$. Conversely, $A_{2}$ increased significantly as the PMOXA concentrations increased from $0 \%$ to $20 \%$ and decreased when the PMOXA concentration increased to $25 \%$. This result provides strong evidence that non-radiative recombination was significantly suppressed after the addition of PMOXA and therefore the portion of radiative recombination within the total recombination was enhanced.

Furthermore, PLQYs of $\mathrm{CsPbBr}_{3}$ films with various concentrations of PMOXA were also investigated to confirm their PL properties. Fig. 2b shows that PLQY of $\mathrm{CsPbBr}_{3}$ film increased from $0.5 \%$ to $18 \%$ when PMOXA concentrations increased from $0 \%$ to $20 \%$. Similarly, the PLQY dropped to $15.6 \%$ when too much PMOXA (25\%) was added to this perovskite system. We attributed the improvement of PLQY after the incorporation of PMOXA to the suppression of non-radiative recombination, which was likely caused by the surface passivation effect from PMOXA, as the electron lone pair in the nitrogen and oxygen atom of PMOXA can coordinate with $\mathrm{Pb}^{2+}$ on the perovskite surface by Lewis base and Lewis acid interactions. ${ }^{54-58}$ However, the PL property dropped after the PMOXA concentration was increased to $25 \%$; this could be attributed to the phase segregation of PMOXA and $\mathrm{CsPbBr}_{3}$ crystals and is discussed below.

Taken together, both the PL lifetime and PLQY results show that $\mathrm{CsPBBr}_{3}$ films with 20\% PMOXA possessed the best PL properties and suggest that this case obtained the best potential for LED applications.

Aside from PL properties, film morphology is another critical factor that governs the final performance of PeLEDs. We therefore used scanning electron microscopy (SEM) and atomic force microscopy (AFM) to study the morphologies of $\mathrm{CsPbBr}_{3}$ films that contain various concentrations of PMOXA. As shown in Fig. 3 and $\mathrm{S} 1, \uparrow$ the pristine $\mathrm{CsPbBr}_{3}$ film had poor film morphology, low film coverage and large film roughness (RMS $=6.9 \mathrm{~nm}$ ), with crystal sizes of hundreds of nanometres; these properties are not suitable for LED application. After the introduction of PMOXA in concentrations of $5 \%$ to $25 \%$ into
$\mathrm{CsPBr}_{3}$ film, high-coverage films with reduced-size nanocrystals were successfully formed, resulting in a small film roughness of approximately $2 \mathrm{~nm}$. However, with concentrations of PMOXA exceeding $25 \%$, the perovskite crystals became large again, which may be attributable to phase segregation between the polymer phase and perovskite phase. Such phase segregation consequently enhanced the non-radiative recombination and thus reduced the PLQY of the perovskite film. We can expect that such a film is also not ideal for LED applications.

The modulation of film morphology by PMOXA additives indicated that PMOXA may influence the formation process of $\mathrm{CsPbBr}_{3}$ crystals. To provide a deeper understanding of such effects, we performed transmission electron microscopy (TEM) to further characterise the crystal evolution in $\mathrm{CsPbBr}_{3}$ film treated with 20\% PMOXA, before and after the annealing process (because the film with 20\% PMOXA had the best potential for use in high-performance LED device). As shown in Fig. 4a, even before annealing, tiny crystals less than $10 \mathrm{~nm}$ in size had already been formed. We identified these as $\mathrm{CsPbBr}_{3}$ crystals based on the appearance of their (210) plane in the magnified image. After annealing, these crystals grew to bigger $\mathrm{CsPbBr}_{3}$ perovskite nanocrystals of tens of nanometres in size, as shown in Fig. $4 \mathrm{~b}$. The magnified image shows a (100) plane of $\mathrm{CsPbBr}_{3}$ nanocrystal with a complete lattice, which illustrates that these nanocrystals were in high quality. ${ }^{59,60}$

According to previous reports that the electron lone pair in $\mathrm{C}=\mathrm{O}$ can coordinate with $\mathrm{Pb}^{2+}$ in perovskite and thus influence the nucleation and growth process of perovskite crystals, ${ }^{20,38}$ we therefore also consider that $\mathrm{C}=\mathrm{O}$ in PMOXA could strongly coordinate with $\mathrm{Pb}^{2+}$ in $\mathrm{PbBr}_{2}$, facilitating the formation of tiny $\mathrm{CsPbBr}_{3}$ crystals in spin-coated films and that such tiny crystals also act as sites of nucleation. During the annealing process, the dissociated $\mathrm{CsBr}$ and $\mathrm{PbBr}_{2}$ can interact with such nucleation sites, resulting in the further growth of $\mathrm{CsPbBr}_{3}$ nanocrystals. Meanwhile, the limited space in the polymer matrix restricted the further growth of $\mathrm{CsPBrr}_{3}$ nanocrystals to less than $100 \mathrm{~nm}$.

To evaluate the EL properties of $\mathrm{CsPbBr}_{3} / \mathrm{PMOXA}$ hybrid films, perovskite LEDs with a device structure of indium oxide 

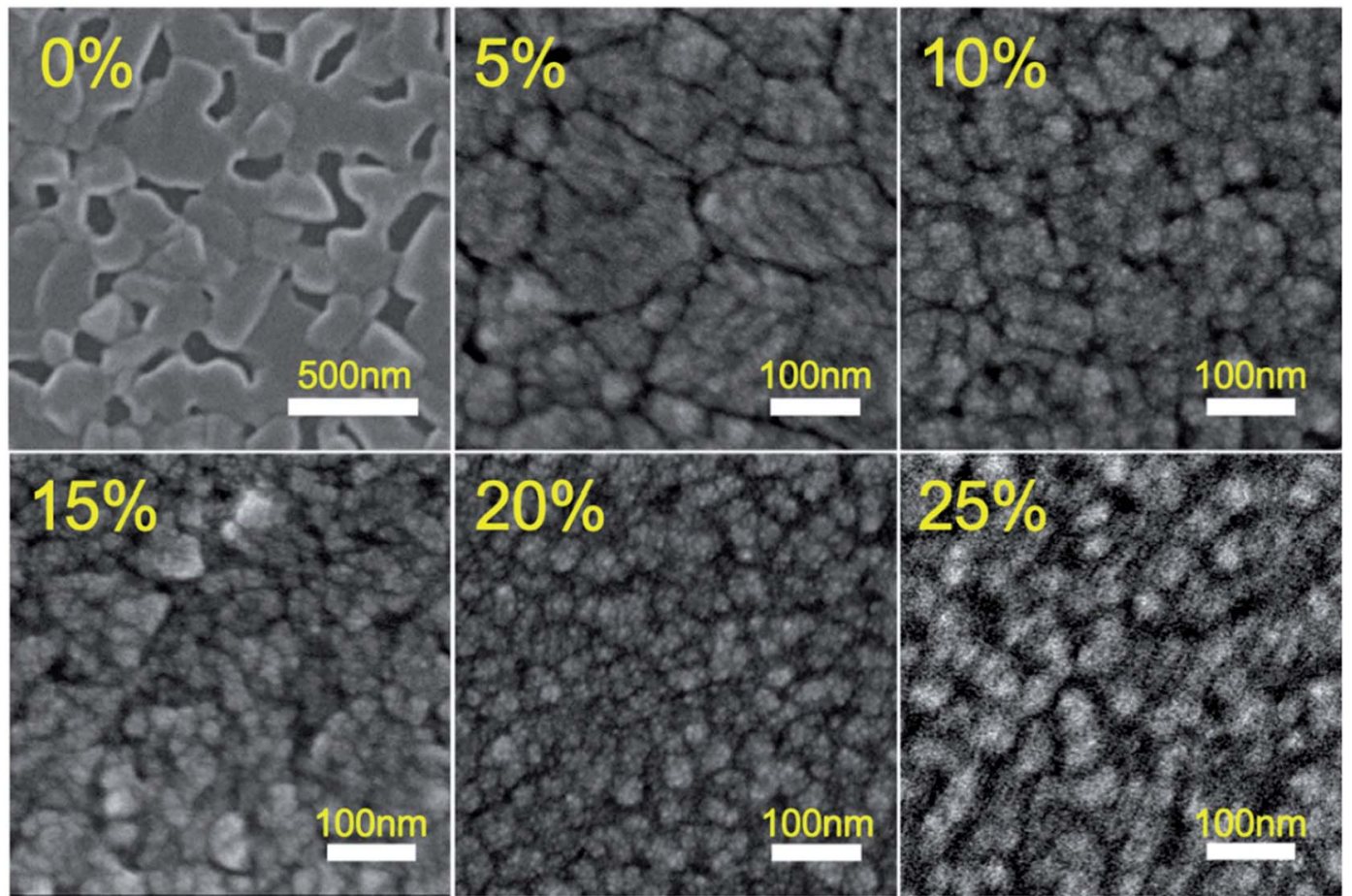

Fig. $3 \mathrm{SEM}$ images of $\mathrm{CsPbBr}_{3}$ films with various concentrations of PMOXA.

(ITO)/PEDOT:PSS/perovskite/TPBi/LiF/Al were fabricated (Fig. 5a), where PEDOT:PSS and TPBi acted as the hole and electron transport layers, respectively. Fig. 5b shows the energy level of each functional layer. Such device architecture presented a proper energy-level alignment of both electron and hole injection to the light-emitting layer. The performances of $\mathrm{CsPbBr}_{3}$ LEDs with various concentrations of PMOXA are summarised in Table 1 and in Fig. 6a and b.

No EL was obtained for films of $0 \%$ and 5\% PMOXA-treated $\mathrm{CsPBBr}_{3}$, because of their poor PL properties, crystal qualities and film morphologies. However, when the concentration of PMOXA was increased from $10 \%$ to $20 \%$, the device performance improved rapidly. The highest luminance, EQE and current efficiency of $16648 \mathrm{~cd} \mathrm{~m}^{-2}, 3.0 \%$ and $10.1 \mathrm{~cd} \mathrm{~A}^{-1}$, respectively, were achieved at relatively low applied voltage in the device containing 20\% PMOXA-treated $\mathrm{CsPbBr}_{3}$. Further increasing the concentration of PMOXA to $25 \%$ resulted in a decrease in device performance. These device performancechanges can be explained by the aforementioned observations: that the film quality and PLQY was improved when we

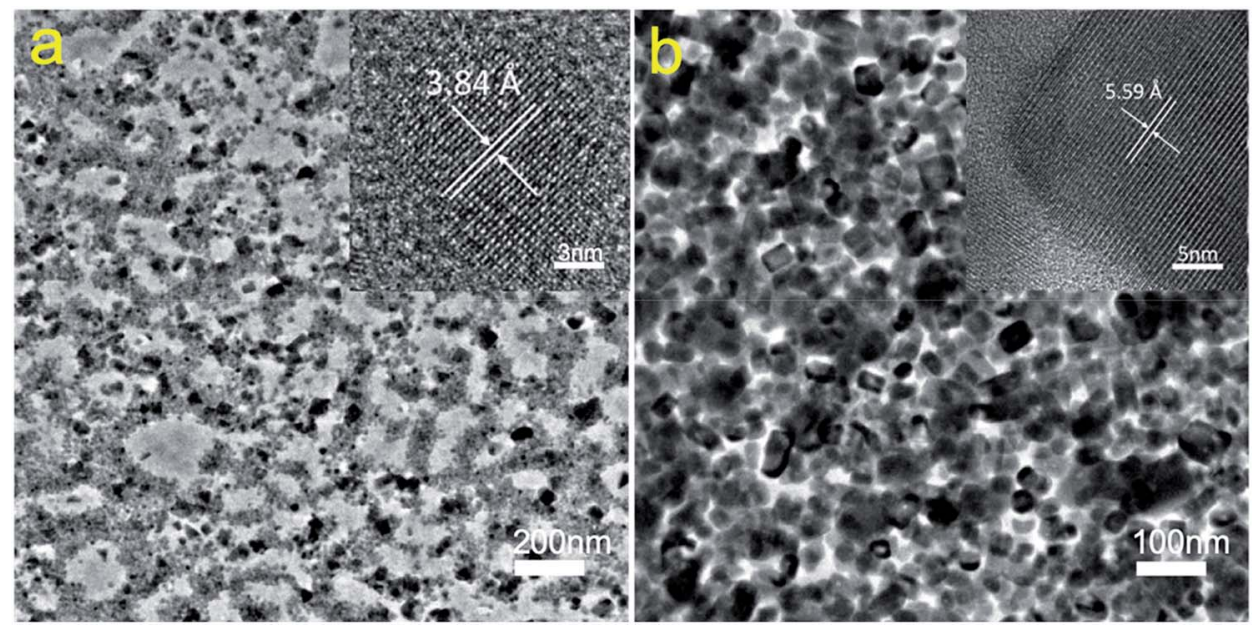

Fig. 4 (a) TEM image of 20\% PMOXA-treated $\mathrm{CsPbBr}_{3}$ film without annealing. Scale bar: $200 \mathrm{~nm}$. Inset image is the high-resolution TEM image of crystal. Scale bar: $3 \mathrm{~nm}$. (b) TEM image of $20 \%$ treated-PMOXA CsPbBr 3 film with annealing. Scale bar: $100 \mathrm{~nm}$. Inset image is the high-resolution TEM image of crystal. Scale bar: $5 \mathrm{~nm}$. 


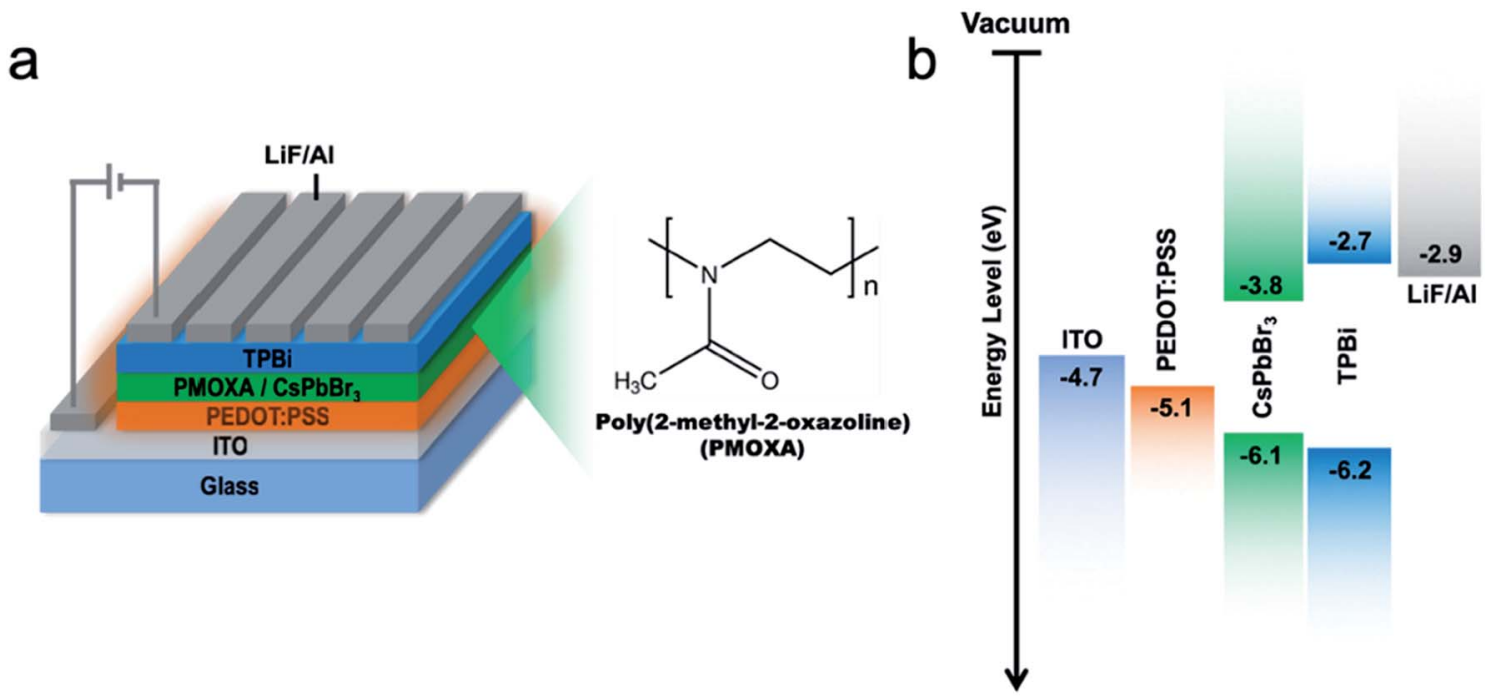

Fig. 5 (a) Schematic device structure. (b) Energy diagram of each layer of the LED device. The energy level of $\mathrm{CsPbBr}_{3}$ are cited from ref. 61.

increased the PMOXA concentration from $0 \%$ to $20 \%$, whereas poorer film quality and PLQY resulted if we further increased the PMOXA concentration to $25 \%$.

The EL emission peak of the 20\% PMOXA-treated $\mathrm{CsPbBr}_{3}$ device was located at $512 \mathrm{~nm}$ with a narrow FWHM of $18 \mathrm{~nm}$, which corresponded to Commission International de $1^{\prime}$ Eclairage (CIE) colour coordinates of $(0.08,0.77)$ (Fig. 6d). As shown in Fig. S2, $\uparrow$ the EL spectra showed no change at a different applied current density, which suggests that such a device displayed excellent spectral stability. In addition, when the device was operated at a high initial luminance of $1000 \mathrm{~cd}$ $\mathrm{m}^{-2}$, a 2.4 hour half-lifetime could be obtained (as shown in Fig. 6c), which represents one of the best results for greenemissive PeLEDs at such a high initial luminance (Table S2†).

In summary, we have demonstrated a simple approach to form high-quality $\mathrm{CsPbBr}_{3}$ perovskite films by treatment with polymer additives. The addition of PMOXA can modify the morphology of perovskite film, reduce the crystal size, passivate crystal surface-traps and improve the PLQY of perovskite film. Also, such polymer additives may coordinate with $\mathrm{Pb}^{2+}$, which could control the nucleation and growth process of perovskite, resulting in the in situ growth of $\mathrm{CsPbBr}_{3}$ nanocrystals. In the optimised conditions of $\mathrm{CsPbBr}_{3}$ film treated with $20 \%$ PMOXA, a highly efficient perovskite LED was fabricated with a maximum EQE of $3.0 \%$ and luminance of $16648 \mathrm{~cd} \mathrm{~m}^{-2}$. The LED also showed a low turn-on voltage of $3.0 \mathrm{~V}$ and CIE of $(0.08$, 0.77 ), which are properties of an excellent green-emissive LED.
More importantly, the LED fabricated from 20\% PMOXA-treated $\mathrm{CsPbBr}_{3}$ presented excellent spectrum stability and a halflifetime of 2.4 hour under an initial luminance of $1000 \mathrm{~cd}$ $\mathrm{m}^{-2}$, highlighting the potential of $20 \%$ PMOXA-treated $\mathrm{CsPbBr}_{3}$-based LEDs for future applications, such as whitelight illuminations and full-colour displays.

\section{Experimental section}

All chemicals were used as received without further purification.

\section{Perovskite precursor}

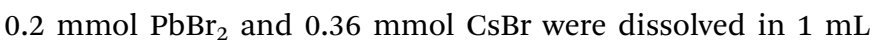
DMSO to form a $0.2 \mathrm{M}$ perovskite precursor solution. Appropriate amounts of PMOXA (Sigma-Aldrich) were dissolved in the resulting $\mathrm{CsPbBr}_{3}$ solutions. The relative weight ratio of $x \%$ PMOXA means $m_{\mathrm{PMOXA}} / m_{\mathrm{CsPbBr}_{3}}=x \%$. The precursor solution was stirred overnight at room temperature.

\section{Film characterisation}

Ultraviolet-visible light absorptions were measured with HP8453 spectrophotometer. The PL spectra were measured with a spectrofluorometer (PerkinElmer LS 55).

AFM (Digital Instrumental [DI] Multimode Nanoscope IIIa) and SEM (ZEISS Merlin) measurements were carried out based on the structure of ITO/PEDOT/perovskite. TEM samples were

Table 1 Perovskite LED properties with various concentrations of PMOXA

\begin{tabular}{|c|c|c|c|c|c|}
\hline PMOXA ratio & $V_{\text {on }}(\mathrm{V})$ & $L_{\max }\left(\mathrm{cd} \mathrm{m}^{-2}\right)$ & $\mathrm{CE}_{\max }\left(\mathrm{cd} \mathrm{A}^{-1}\right)$ & $\mathrm{EQE}_{\max }(\%)$ & $\operatorname{CIE}(x, y)$ \\
\hline $10 \%$ & 3.1 & 11452 & 5.4 & 1.8 & $(0.06,0.74)$ \\
\hline $15 \%$ & 3.0 & 13772 & 6.8 & 2.2 & $(0.07,0.75)$ \\
\hline $25 \%$ & 3.1 & 2693 & 7.8 & 2.2 & $(0.09,0.78)$ \\
\hline
\end{tabular}



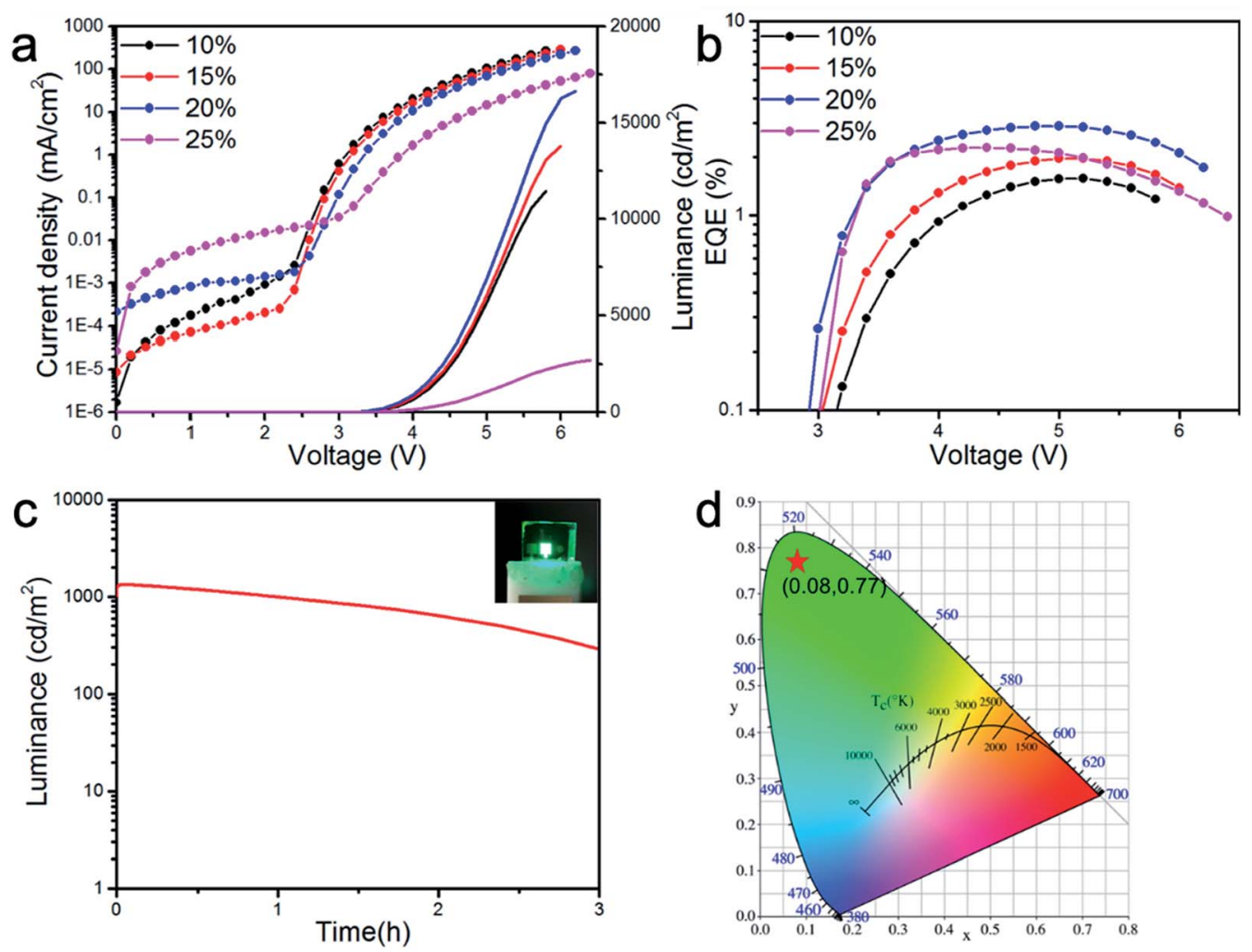

Fig. 6 (a) Current density and luminance versus voltage characteristics of $\mathrm{CsPbBr}_{3}$ LEDs with various concentrations of PMOXA. Solid lines and dotted lines correspond to luminance and current density, respectively. (b) EQE versus voltage characteristic of $\mathrm{Cs}_{\mathrm{PbBr}} \mathrm{LEDs}$ with various concentrations of PMOXA. (c) Stability measurement of $\mathrm{CsPbBr}_{3}$ LED with $20 \% \mathrm{PMOXA}$. Initial luminance was $1000 \mathrm{~cd} \mathrm{~m}^{-2}$. The inserted image is the photo of such LED illuminated at $1000 \mathrm{~cd} \mathrm{~m}^{-2}$. (d) CIE coordinate of $\mathrm{CsPbBr}_{3}$ LED with $20 \%$ PMOXA.

prepared according to the structure of ITO/PMMA/PEDOT:PSS/ perovskite. The PMMA film was dissolved in chlorobenzene, and the PEDOT:PSS/perovskite film could be separated from the substrate, which was suitable for TEM measurement. The TEM samples were measured by JEM-2100F. XRD measurement was carried out based on the structure of ITO/PEDOT/perovskite by an X-ray diffractometer (PANalytical X'pertPRO) equipped with $\mathrm{Cu}-\mathrm{K} \alpha \mathrm{X}$-ray tube.

\section{PLQY and PL lifetime measurement}

PLQY values were obtained from perovskite films on glass at the excitation wavelength of $365 \mathrm{~nm}$ using a calibrated integrating sphere. Time-resolved PL lifetime measurements were performed with a transient photoluminescence spectrometer (FLS980, Edinburgh Instruments) equipped with a timecorrelated single-photon counting unit. A picosecond laser diode $(405 \mathrm{~nm}$, pulse width $=50 \mathrm{ps}$ ) was used as the excitation source.

\section{Perovskite LED device fabrication}

ITO-coated glass substrates were cleaned successively by sonication in detergent, acetone, deionised water and isopropyl alcohol. After $4 \mathrm{~min}$ of oxygen plasma treatment, diluted PEDOT:PSS (Clevios, 4083) was spin-coated on ITO-coated glass substrate at $3000 \mathrm{rpm}$ for $30 \mathrm{~s}$ and then annealed at $150{ }^{\circ} \mathrm{C}$ for
$15 \mathrm{~min}$ in a laboratory atmosphere; $0.2 \mathrm{M}$ perovskite precursor solution was then spin-coated on PEDOT:PSS film at $3500 \mathrm{rpm}$ for $30 \mathrm{~s}$ and annealed for $20 \mathrm{~min}$ in a glovebox at $130{ }^{\circ} \mathrm{C}$. A 50 nm-thick TPBi was evaporated onto the perovskite layer, followed by the deposition of $\operatorname{LiF}(1 \mathrm{~nm})$ and $\mathrm{Al}(120 \mathrm{~nm})$ by thermal deposition in a vacuum chamber (pressure $\approx 2 \times 10^{-6}$ Torr). The device's active area was $0.1 \mathrm{~cm}^{2}$.

\section{Perovskite LED device characterisation}

Current density-voltage-radiance measurement was carried out with a Keithley 2400 source measurement unit and a Konica Minolta Chroma Meter CS-200. The electroluminescence spectra and CIE coordinates were recorded with an Ocean Optics USB $2000+$ spectrometer. The external quantum efficiency values were calculated assuming a Lambertian emission profile. All the perovskite LEDs were measured in air after encapsulation.

\section{Author contributions}

Cai W. fabricated the perovskite LEDs and carried out the device characterizations. Cai W., Chen Z., and Chen D. carried out the perovskite film characterizations. Chen Z. and Cai W. analyzed the data and wrote the manuscript. Chen Z. and Yip H.-L. led 
the project. Yip H.-L., Su S., Xu Q. and Cao Y. supervised the research.

\section{Conflicts of interest}

The authors declare that they have no conflict of interest.

\section{Acknowledgements}

This study was financially supported by the Ministry of Science and Technology of the People's Republic of China (No. 2017YFA0206600), the National Natural Science Foundation of China (No. 21761132001, 51573057 and 91733302) and China Postdoctoral Science Foundation (No. 2019M650197).

\section{References}

1 Z. Wang, Q. Lin, B. Wenger, M. G. Christoforo, Y.-H. Lin, M. T. Klug, M. B. Johnston, L. M. Herz and H. J. Snaith, Nat. Energy, 2018, 3, 855-861.

2 Z. Yang, Y. Deng, X. Zhang, S. Wang, H. Chen, S. Yang, J. Khurgin, N. X. Fang, X. Zhang and R. Ma, Adv. Mater., 2018, 30, 1704333.

3 T. J. S. Evans, A. Schlaus, Y. Fu, X. Zhong, T. L. Atallah, M. S. Spencer, L. E. Brus, S. Jin and X. Y. Zhu, Adv. Opt. Mater., 2018, 6, 1700982.

4 L. Protesescu, S. Yakunin, M. I. Bodnarchuk, F. Krieg, R. Caputo, C. H. Hendon, R. X. Yang, A. Walsh and M. V. Kovalenko, Nano Lett., 2015, 15, 3692-3696.

5 Z. Chen, C. Zhang, X. F. Jiang, M. Liu, R. Xia, T. Shi, D. Chen, Q. Xue, Y. J. Zhao, S. Su, H. L. Yip and Y. Cao, Adv. Mater., 2017, 29, 1603157.

6 Z. Xiao, R. A. Kerner, L. Zhao, N. L. Tran, K. M. Lee, T.-W. Koh, G. D. Scholes and B. P. Rand, Nat. Photonics, 2017, 11, 108-115.

7 X. Li, Y. Wu, S. Zhang, B. Cai, Y. Gu, J. Song and H. Zeng, Adv. Funct. Mater., 2016, 26, 2435-2445.

8 G. R. Yettapu, D. Talukdar, S. Sarkar, A. Swarnkar, A. Nag, P. Ghosh and P. Mandal, Nano Lett., 2016, 16, 4838-4848.

9 Y. Cao, N. Wang, H. Tian, J. Guo, Y. Wei, H. Chen, Y. Miao, W. Zou, K. Pan, Y. He, H. Cao, Y. Ke, M. Xu, Y. Wang, M. Yang, K. Du, Z. Fu, D. Kong, D. Dai, Y. Jin, G. Li, H. Li, Q. Peng, J. Wang and W. Huang, Nature, 2018, 562, 249-253.

10 T. Chiba, Y. Hayashi, H. Ebe, K. Hoshi, J. Sato, S. Sato, Y.-J. Pu, S. Ohisa and J. Kido, Nat. Photonics, 2018, 12, 681687.

11 K. Lin, J. Xing, L. N. Quan, F. P. G. de Arquer, X. Gong, J. Lu, L. Xie, W. Zhao, D. Zhang, C. Yan, W. Li, X. Liu, Y. Lu, J. Kirman, E. H. Sargent, Q. Xiong and Z. Wei, Nature, 2018, 562, 245-248.

12 H. Cho, S.-H. Jeong, M.-H. Park, Y.-H. Kim, C. Wolf, C.-L. Lee, J. H. Heo, A. Sadhanala, N. Myoung, S. Yoo, S. H. Im, R. H. Friend and T.-W. Lee, Science, 2015, 350, 1222-1225.

13 X. Yang, X. Zhang, J. Deng, Z. Chu, Q. Jiang, J. Meng, P. Wang, L. Zhang, Z. Yin and J. You, Nat. Commun., 2018, 9, 570-578.
14 N. Wang, L. Cheng, R. Ge, S. Zhang, Y. Miao, W. Zou, C. Yi, Y. Sun, Y. Cao, R. Yang, Y. Wei, Q. Guo, Y. Ke, M. Yu, Y. Jin, Y. Liu, Q. Ding, D. Di, L. Yang, G. Xing, H. Tian, C. Jin, F. Gao, R. H. Friend, J. Wang and W. Huang, Nat. Photonics, 2016, 10, 699-704.

15 X. Zhao and N.-G. Park, Photonics, 2015, 2, 1139-1151.

16 Y. H. Kim, H. Cho, J. H. Heo, T. S. Kim, N. Myoung, C. L. Lee, S. H. Im and T. W. Lee, Adv. Mater., 2015, 27, 1248-1254.

17 Y.-H. Kim, C. Wolf, Y.-T. Kim, H. Cho, W. Kwon, S. Do, A. Sadhanala, C. G. Park, S.-W. Rhee, S. H. Im, R. H. Friend and T.-W. Lee, ACS Nano, 2017, 11, 6586-6593. 18 J.-W. Lee, Y. J. Choi, J.-M. Yang, S. Ham, S. K. Jeon, J. Y. Lee, Y.-H. Song, E. K. Ji, D.-H. Yoon, S. Seo, H. Shin, G. S. Han, H. S. Jung, D. Kim and N.-G. Park, ACS Nano, 2017, 11, 3311-3319.

19 L. Dimesso, C. Wittich, T. Mayer and W. Jaegermann, J. Mater. Sci., 2019, 54, 2001-2015.

20 Z. Song, N. Shrestha, S. C. Watthage, G. K. Liyanage, Z. S. Almutawah, R. H. Ahangharnejhad, A. B. Phillips, R. J. Ellingson and M. J. Heben, J. Phys. Chem. Lett., 2018, 9, 6312-6320.

21 R. K. Misra, S. Aharon, B. Li, D. Mogilyansky, I. Visoly-Fisher, L. Etgar and E. A. Katz, J. Phys. Chem. Lett., 2015, 6, 326-330. 22 R. K. Singh, R. Kumar, A. Kumar, N. Jain, R. K. Singh and J. Singh, J. Alloys Compd., 2018, 743, 728-736.

23 Y.-H. Kim, H. Cho, J. H. Heo, S. H. Im and T.-W. Lee, Curr. Appl. Phys., 2016, 16, 1069-1074.

24 J. Pan, Y. Shang, J. Yin, M. De Bastiani, W. Peng, I. Dursun, L. Sinatra, A. M. El-Zohry, M. N. Hedhili, A. H. Emwas, O. F. Mohammed, Z. Ning and O. M. Bakr, J. Am. Chem. Soc., 2018, 140, 562-565.

25 W. Cai, Z. Chen, Z. Li, L. Yan, D. Zhang, L. Liu, Q.-h. Xu, Y. Ma, F. Huang, H.-L. Yip and Y. Cao, ACS Appl. Mater. Interfaces, 2018, 10, 42564-42572.

26 Y. Tian, C. Zhou, M. Worku, X. Wang, Y. Ling, H. Gao, Y. Zhou, Y. Miao, J. Guan and B. Ma, Adv. Mater., 2018, 30, e1707093.

27 J. Song, J. Li, X. Li, L. Xu, Y. Dong and H. Zeng, Adv. Mater., 2015, 27, 7162-7167.

28 L. Zhang, X. Yang, Q. Jiang, P. Wang, Z. Yin, X. Zhang, H. Tan, Y. M. Yang, M. Wei, B. R. Sutherland, E. H. Sargent and J. You, Nat. Commun., 2017, 8, 15640.

29 Y. Shang, G. Li, W. Liu and Z. Ning, Adv. Funct. Mater., 2018, 28, 1801193.

30 J. Li, L. Xu, T. Wang, J. Song, J. Chen, J. Xue, Y. Dong, B. Cai, Q. Shan, B. Han and H. Zeng, Adv. Mater., 2017, 29, 1603885.

31 J. Xing, Y. Zhao, M. Askerka, L. N. Quan, X. Gong, W. Zhao, J. Zhao, H. Tan, G. Long, L. Gao, Z. Yang, O. Voznyy, J. Tang, Z. H. Lu, Q. Xiong and E. H. Sargent, Nat. Commun., 2018, 9, 3541.

32 M. K. Gangishetty, S. Hou, Q. Quan and D. N. Congreve, Adv. Mater., 2018, 30, e1706226.

33 M. Yuan, L. N. Quan, R. Comin, G. Walters, R. Sabatini, O. Voznyy, S. Hoogland, Y. Zhao, E. M. Beauregard, P. Kanjanaboos, Z. Lu, D. H. Kim and E. H. Sargent, Nat. Nanotechnol., 2016, 11, 872-877. 
34 G. Li, F. W. Rivarola, N. J. Davis, S. Bai, T. C. Jellicoe, F. de la Pena, S. Hou, C. Ducati, F. Gao, R. H. Friend, N. C. Greenham and Z. K. Tan, Adv. Mater., 2016, 28, 35283534.

35 J. Li, X. Shan, S. G. Bade, T. Geske, Q. Jiang, X. Yang and Z. Yu, J. Phys. Chem. Lett., 2016, 4059-4066.

36 H. Cho, C. Wolf, J. S. Kim, H. J. Yun, J. S. Bae, H. Kim, J. M. Heo, S. Ahn and T. W. Lee, Adv. Mater., 2017, 29, 1700579.

37 J. Shamsi, P. Rastogi, V. Caligiuri, A. L. Abdelhady, D. Spirito, L. Manna and R. Krahne, ACS Nano, 2017, 11, 10206-10213.

38 C. Wu, Y. Zou, T. Wu, M. Ban, V. Pecunia, Y. Han, Q. Liu, T. Song, S. Duhm and B. Sun, Adv. Funct. Mater., 2017, 27, 1700338.

39 J. Pan, Y. Shang, J. Yin, M. De Bastiani, W. Peng, I. Dursun, L. Sinatra, A. M. El-Zohry, M. N. Hedhili, A. H. Emwas, O. F. Mohammed, Z. Ning and O. M. Bakr, J. Am. Chem. Soc., 2018, 140, 562-565.

40 M. Imran, V. Caligiuri, M. Wang, L. Goldoni, M. Prato, R. Krahne, L. De Trizio and L. Manna, J. Am. Chem. Soc., 2018, 140, 2656-2664.

41 D. K. Sharma, S. Hirata, V. Biju and M. Vacha, ACS Nano, 2019, 13, 624-632.

42 Y. Shen, L. P. Cheng, Y. Q. Li, W. Li, J. D. Chen, S. T. Lee and J. X. Tang, Adv. Mater., 2019, e1901517.

43 B. Jeong, H. Han, Y. J. Choi, S. H. Cho, E. H. Kim, S. W. Lee, J. S. Kim, C. Park, D. Kim and C. Park, Adv. Funct. Mater., 2018, 28, 1706401.

44 J. Li, X. Shan, S. G. Bade, T. Geske, Q. Jiang, X. Yang and Z. Yu, J. Phys. Chem. Lett., 2016, 4059-4066.

45 Z. Chen, Z. Li, C. Zhang, X. F. Jiang, D. Chen, Q. Xue, M. Liu, S. Su, H. L. Yip and Y. Cao, Adv. Mater., 2018, 30, e1801370.

46 G. Li, Z. K. Tan, D. Di, M. L. Lai, L. Jiang, J. H. Lim, R. H. Friend and N. C. Greenham, Nano Lett., 2015, 15, 2640-2644.
47 Y. Ling, Y. Tian, X. Wang, J. C. Wang, J. M. Knox, F. PerezOrive, Y. Du, L. Tan, K. Hanson, B. Ma and H. Gao, Adv. Mater., 2016, 28, 8983-8989.

48 J. Li, S. G. Bade, X. Shan and Z. Yu, Adv. Mater., 2015, 27, 5196-5202.

49 R. J. Sutton, G. E. Eperon, L. Miranda, E. S. Parrott, B. A. Kamino, J. B. Patel, M. T. Hörantner, M. B. Johnston, A. A. Haghighirad, D. T. Moore and H. J. Snaith, Adv. Energy Mater., 2016, 6, 1502458.

50 X. Chang, W. Li, L. Zhu, H. Liu, H. Geng, S. Xiang, J. Liu and H. Chen, ACS Appl. Mater. Interfaces, 2016, 8, 33649-33655.

51 T. Burwig, W. Fränzel and P. Pistor, J. Phys. Chem. Lett., 2018, 9, 4808-4813.

52 Z. Shi, S. Li, Y. Li, H. Ji, X. Li, D. Wu, T. Xu, Y. Chen, Y. Tian, Y. Zhang, C. Shan and G. Du, ACS Nano, 2018, 12, 1462-1472. 53 H. Cho, J. S. Kim, C. Wolf, Y. H. Kim, H. J. Yun, S. H. Jeong, A. Sadhanala, V. Venugopalan, J. W. Choi, C. L. Lee, R. H. Friend and T. W. Lee, ACS Nano, 2018, 12, 2883-2892. 54 L. Song, X. Guo, Y. Hu, Y. Lv, J. Lin, Z. Liu, Y. Fan and X. Liu, J. Phys. Chem. Lett., 2017, 8, 4148-4154.

55 N. Wang, L. Cheng, J. Si, X. Liang, Y. Jin, J. Wang and W. Huang, Appl. Phys. Lett., 2016, 108, 141102.

56 N. Ahn, D. Y. Son, I. H. Jang, S. M. Kang, M. Choi and N. G. Park, J. Am. Chem. Soc., 2015, 137, 8696-8699.

57 X. Cao, C. Li, Y. Li, F. Fang, X. Cui, Y. Yao and J. Wei, Nanoscale, 2016, 8, 19804-19810.

58 Y. Jo, K. S. Oh, M. Kim, K.-H. Kim, H. Lee, C.-W. Lee and D. S. Kim, Adv. Mater. Interfaces, 2016, 3, 1500768.

59 J. Zhang, L. Fan, J. Li, X. Liu, R. Wang, L. Wang and G. Tu, Nano Res., 2019, 12, 121-127.

60 J. Zhang, L. Zhang, P. Cai, X. Xue, M. Wang, J. Zhang and G. Tu, Nano Energy, 2019, 62, 434-441.

61 Y. Tan, Y. Zou, L. Wu, Q. Huang, D. Yang, M. Chen, M. Ban, C. Wu, T. Wu, S. Bai, T. Song, Q. Zhang and B. Sun, ACS Appl. Mater. Interfaces, 2018, 10, 3784-3792. 